\title{
Condensing embryology teaching for medical students: can it be taught in 2 hours?
}

This article was published in the following Dove Press journal: Advances in Medical Education and Practice

\section{Fawz Kazzazi \\ Jonathan Bartlett}

School of Clinical Medicine, University of Cambridge, Cambridge, UK

Correspondence: Fawz Kazzazi School of Clinical Medicine, University of Cambridge, 37 Grange Road, Leckhampton House, Cambridge, CB2 IRH, UK

Tel +44775 422005

Email fk276@cam.ac.uk
Introduction: Embryology forms a valuable part of the medical school curriculum. However, medical students traditionally struggle with revising embryology and appreciating its relevance. Condensing the teaching content, implementing peer-teaching methods, and increasing clinical focus in curricula have been suggested as methods to improve student engagement.

Methods: Medical students at two universities were taught a condensed version of the embryological curriculum in 2 hours by final-year medical students. Students' confidence with the topics covered in the embryological curricula was assessed using anonymized precourse and postcourse questionnaires. Students were asked to further evaluate the quality, delivery, and content of the teaching in the postcourse questionnaire and were given the opportunity to provide written comments. All questions consisted of a statement stem and a five-point Likert scale.

Results: Students scored significantly higher levels of confidence with embryology after implementation of the course. They found the talk to be effectively delivered, clear, and relevant to their examinations.

Conclusion: We have demonstrated that it is possible to design and produce an embryology teaching program that covers an undergraduate embryology curriculum in a chronological systems-based manner in 2 hours with successful results.

Keywords: embryology, medical students, teaching, condensed

\section{Introduction}

Embryology forms an integral part of the preclinical basic science teaching in medical curriculums. Its learning outcomes have applications in general surgery, pediatrics, craniofacial surgery, obstetrics and gynecology, and ear-nose-throat surgery. Yet, it is still an area that is often overlooked by medical students. ${ }^{1}$ The rapid development of the field increases the difficulty in ascertaining the level of detail required for the medical course. ${ }^{2}$ Although speakers in embryology appear confident at teaching the course, ${ }^{3}$ these results are discordant with the opinions of medical students as to the effective delivery of the course. ${ }^{4,5}$ Educators have suggested methods of improving the course material to include the following: improved animations and greater focus on clinical application; ${ }^{3,6}$ this is consistent with thoughts that later teaching of medicine (ie, in clinical parts of the course) would be more effective. ${ }^{4,6}$ Additionally, peer teaching has been utilized as a means of increasing student confidence in the understanding of embryology, ${ }^{7}$ and it has established benefits for both the tutor and tutee. ${ }^{8}$ These suggestions and approaches are of increased relevance with the decreased allocation of time and resources to embryology teaching across medical schools. ${ }^{6}$ 
Designing a course is an arduous task that involves a multitude of considerations. The length of the course has to be suitable to maintain attention while providing sufficient levels of detail. ${ }^{9}$ The method and delivery of the teaching should be engaging but insightful. With reduced time frames, it becomes more difficult to engage in problem-based learning activities and maintain content. In a topic such as embryology, where specialist terms are used in isolation and rarely seen elsewhere in medicine, it is paramount to characterize definitions early and ensure maintained understanding through repetition. To effectively address both visual learners and those that learn through didactic teaching, slide sets must be tailored to contain both these elements or re-emphasize key points - first through speech/text and then via illustrations. Despite these challenges, it is certainly achievable to create an illustrative didactic and case-based teaching course. A self-contained systems model course is already established as an effective technique in which to teach embryology. ${ }^{2}$

As such, our goal was to teach embryology in a chronological systems-based manner, finishing each system with the clinical consequences of these developmental processes, and to do so effectively in a single session.

\section{Methods}

\section{Study design}

This was a combined quantitative-qualitative research study. Analysis involved assessment of quantitative and qualitative data from structured feedback questionnaires.

\section{Study participants}

Students at two universities in the UK (Birmingham and Cambridge) took part in the study. The participants were medical students in their first year of study (matriculated 2016). All students had already been lectured on embryology by their medical schools. The course created in this study was endorsed by the student medical societies at both universities. The lecture was publicized as the "Embryology crash course" and delivered approximately 30 days before their end-of-year examinations (in April and May 2017, respectively). No fees or contributions were received for providing the lectures.

Students were not required to provide consent to attend the course as it was part of their timetables.

\section{Course design}

A focus group of 12 students was used to determine an adequate duration for the course. The consensus was that a total time of 2 hours was reasonable when considering student attention, likelihood of attendance, and content. After evaluating the curricula from each medical school, the course was designed to cover the following topics:

1. The processes of fertilization and implantation

2. Development of placental support

3. Somitogenesis

4. Principles of organ formation

5. Development of the neural system

6. Development of the gastrointestinal systems and lungs

7. Development of the heart

8. Congenital abnormalities

\section{Course delivery}

The course material was divided into two halves, with a 10-minute comfort break between them, and delivered by two sixth-year medical students. In the first half, components 1-3 were taught, and in the second half, components 4-7 were the focus. The information regarding "Congenital abnormalities" was distributed throughout the talk - explained at the end of each relevant section. The talk was the form of a PowerPoint presentation, each slide consisting of either bullet points (maximum 5) or diagrams (or both). The PowerPoint was accessible during the lecture through a download link given at the start of the talk. There was little additional information to note down that was not present in the slides. Points that we believed were more commonly examined were highlighted.

\section{Data collection}

On entering the lecture theater, students were given an anonymous precourse questionnaire assessing their confidence with each topic using a five-point Likert scale (Figure S1). At the end of the course, students were given an anonymous postcourse questionnaire (Figure S2) with the same questions as before. Additionally, this version included questions that asked them to evaluate the quality, delivery, and content of the teaching, again using five-point Likert scales. With the second questionnaire, students were also given the opportunity to leave any written feedback or comments. When assessing confidence, the five-point Likert scales used the following scoring metrics:

$$
\begin{aligned}
& 1 \text { - Very poor } \\
& 2 \text { - Poor } \\
& 3 \text { - Neither poor nor good } \\
& 4 \text { - Good } \\
& 5 \text { - Very good }
\end{aligned}
$$

When evaluating the course, the five-point Likert scales utilized the following scoring metrics: 
1 - Strongly disagree

2 - Disagree

3 - Neither agree nor disagree

4 - Agree

5 - Strongly agree

\section{Data analysis}

The questionnaire responses were collated and recorded in Microsoft Excel. Numerical responses were analyzed using FigurePad $^{\mathrm{TM}}$ (Prism 7; Graphpad Software Inc., La Jolla, CA, USA) software. Qualitative comments were recorded and grouped as "positive feedback," "recommendations," or "negative feedback."

To ensure that differences were not university specific, column statistics and Kolmogorov-Smirnov tests were repeated for individual groups. These included the following:

1. Birmingham vs Cambridge precourse scores

2. Birmingham precourse vs postcourse scores

3. Cambridge precourse vs postcourse scores

Baseline scores were similar in both groups of students and there was no significant difference between the precourse scores at both universities, reflecting consistent levels of teaching at both medical schools and therefore allowing grouped analyses.

For each dataset (precourse and postcourse) and topic (eg, somitogenesis), column statistics and normality tests (D'Agostino and Pearson) were completed. Because of the ordinal nature of the data, frequency tables were created. Cumulative distributions were analyzed using KolmogorovSmirnov tests. This was used instead of mean values as the discrete scoring would make interpretation of interim values difficult. Additionally, the results were not normally distributed and the small ranges meant that comparison of median values was inappropriate.

The results of the Kolmogorov-Smirnov tests were used to compare the outcomes before and after the course.

\section{Results}

\section{Precourse scores}

Before the course, the majority of students rated their knowledge as "Neither good nor poor" (equivalent to 3) or worse in all topics, apart from "Development of placental support," for which the majority rated their knowledge as "Poor" (equivalent to 2) or worse (Figure 1A-H). Before the course, students were most confident with teaching regarding the "Development of the heart" (Tables 1 and 2).

\section{Postcourse scores}

The delivery of the lecture was completed in 105 minutes at Birmingham and 110 minutes at Cambridge. After completion of the course, frequency distribution of the survey responses significantly improved $(<0.001$; Table 1 , Figure $1 \mathrm{~A}-\mathrm{H}$ ), demonstrating a greater understanding of the course topics. Both median and mean scores improved across all eight themes after administration of the course. Following the course, higher proportions of students rated their knowledge as "Good" or "Very good" for each topic (Table 2). In all topics, over twice as many students were more confident (defined as knowledge of "Good" or "Very good") than before the course. With the exception of "The processes of fertilization and implantation" and "Development of the neural system," over $90 \%$ of students rated their knowledge as "Good" or "Very good." In these two instances where the proportion of "confident" students was not above $90 \%(81 \%$ and $83 \%)$, the relative increase in scores was over threefold (3.7 and 3.3).

\section{Student feedback}

A total of 29 written feedback comments were received. When categorized, 21 were "positive," 7 were "suggestions," and 1 was "negative." The "negative" feedback commented on additional information that was provided but not in the curriculum, referring to one slide as "confusing." All of the suggestions, apart from one, were that more time should be taken to explain "The processes of fertilization and implantation" phases. This is reflected in both the pre- and postcourse scores as an area of embryology that students struggle more with, receiving the lowest pre- and postcourse scores. The remaining suggestions stated that the presentation required more photos/diagrams to target the visually focused learners. Positive feedback included multiple messages of thanks for delivering the course and "simplifying" embryology. Students appreciated the ability to download the lecture notes, as it meant they were able to listen; however, good wireless connection is vital for this.

With our postcourse feedback quantitative questionnaire, the students "Agreed" that the course was "enjoyable." For the remaining parameters, the students "Strongly agreed" that (Table 3)

1. The content was appropriate and relevant

2. The course was well structured

3. The course was well taught

4. The materials, content, and teaching were of high qualities 
A Processes of fertilization and implant

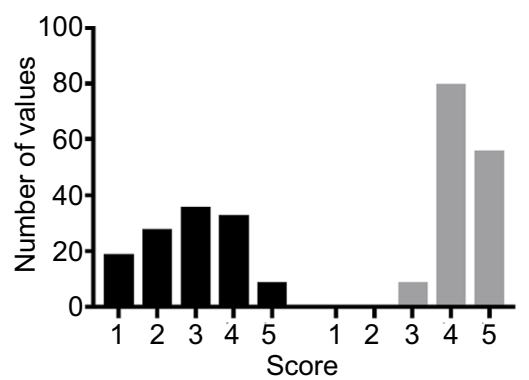

B Development of placental support

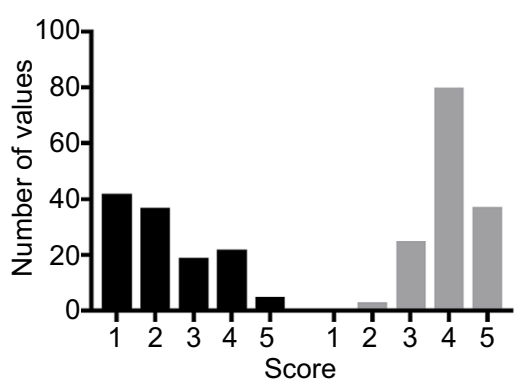

C
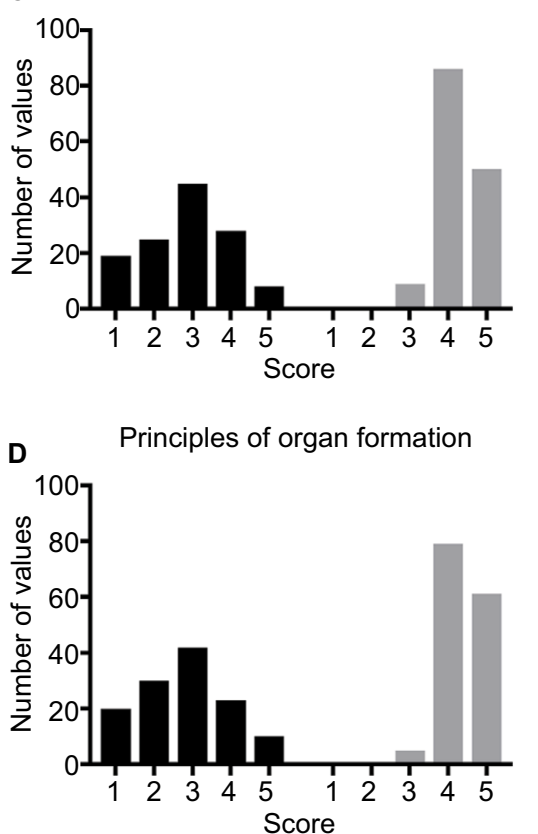

E
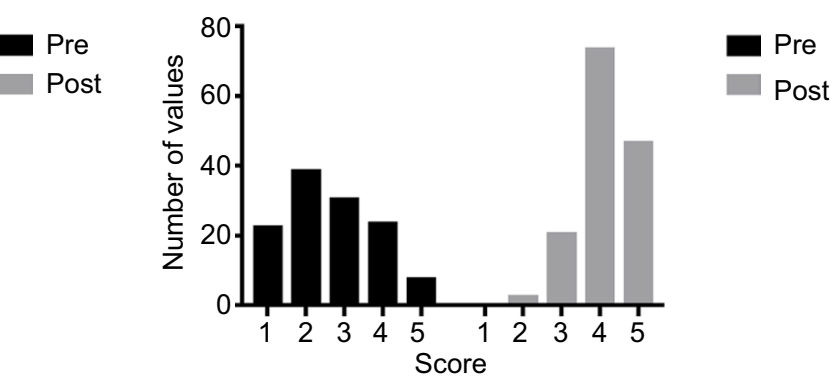

$\mathbf{F}$

Pre

Post

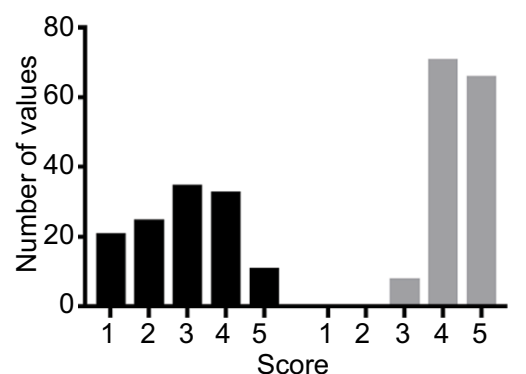

Pre

Post

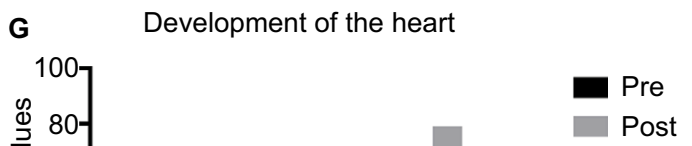

Pre
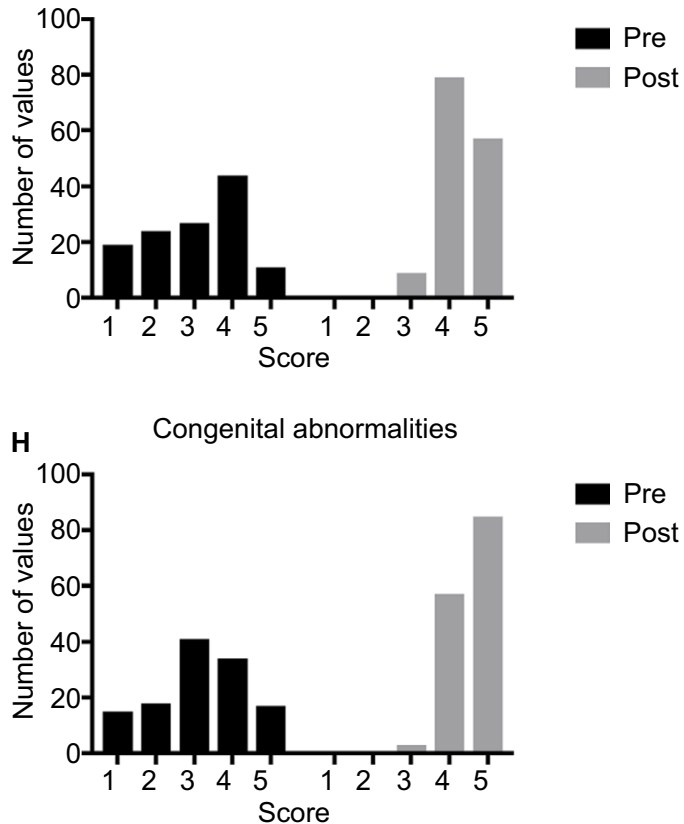

Figure I Student confidence scores before and after administration of the course.

Notes: (A) Histogram depicting the distribution of student scores for the "process of fertilization and implant" component before (pre) and after (post) the course. (B) Histogram depicting the distribution of student scores for the "development of placental support" component before and after the course. (C) Histogram depicting the distribution of student scores for the "somitogenesis" component before and after the course. (D) Histogram depicting the distribution of student scores for the "principles of organ formation" component before and after the course. (E) Histogram depicting the distribution of student scores for the "development of the neural system" component before and after the course. (F) Histogram depicting the distribution of student scores for the "development of the gastrointestinal system and lungs" component before and after the course. (G) Histogram depicting the distribution of student scores for the "development of the heart" component before and after the course. (H) Histogram depicting the distribution of student scores for the "congenital abnormalities" component before and after the course.

Abbreviation: $\mathrm{Gl}$, gastrointestinal.

\section{Discussion}

This study demonstrates that it is possible to teach the embryology required for preclinical medical courses in a clear and concise manner. Organizing the course with a systems-based chronological approach lends itself very well to this shortened format as it allows the introduction of terms and the return to key themes.

Overall, students demonstrated poor confidence with their knowledge of embryology before the course. While this can in part be explained by the fact that these student's 
Table I Results of student scoring for confidence with embryology modules before and after the course (UK, 20I7)

\begin{tabular}{|c|c|c|c|c|c|}
\hline \multirow[t]{2}{*}{ Question } & \multicolumn{2}{|c|}{$\begin{array}{l}\text { Precourse } \\
n=125\end{array}$} & \multicolumn{2}{|c|}{$\begin{array}{l}\text { Postcourse } \\
n=145\end{array}$} & \multirow[t]{2}{*}{$\begin{array}{l}\text { Significantly different? } \\
\text { (Kolmogorov-Smirnov test) }\end{array}$} \\
\hline & Mean & Median & Mean & Median & \\
\hline I. Fertilization/implantation & 2.88 & 3 & 4.32 & 4 & Yes*** \\
\hline 2. Early development/placental & 2.23 & 2 & 4.04 & 4 & Yes*** \\
\hline 3. Somitogenesis & 2.85 & 3 & 4.28 & 4 & Yes*** \\
\hline 4. Organ formation & 2.78 & 3 & 4.39 & 4 & Yes*** \\
\hline 5. Neural system & 2.64 & 3 & 4.13 & 4 & Yes*** \\
\hline 6. Gl/lungs & 2.90 & 3 & 4.40 & 4 & Yes*** \\
\hline 7. Heart & 3.03 & 3 & 4.33 & 4 & Yes*** \\
\hline 8. Congenital defects & 2.95 & 3 & 4.57 & 5 & Yes*** \\
\hline
\end{tabular}

Note: $* * * p<0.001$.

Abbreviation: $\mathrm{Gl}$, gastrointestinal.

Table 2 Proportion of students who score a 4 or above before and after the course (a score of 4 reflects confidence with the component; UK, 20I7)

\begin{tabular}{llll}
\hline Question & \multicolumn{2}{c}{ Students scoring $\mathbf{2 4}$ (\%) } & $\begin{array}{l}\text { Relative } \\
\text { increase }\end{array}$ \\
\cline { 2 - 3 } & Precourse & Postcourse & \\
\hline I. Fertilization/implantation & 33.6 & 93.8 & 2.8 \\
2. Early development/placental & 21.6 & 80.6 & 3.7 \\
3. Somitogenesis & 28.8 & 93.8 & 3.3 \\
4. Organ formation & 26.4 & 96.6 & 3.7 \\
5. Neural system & 25.6 & 83.4 & 3.3 \\
6. GI/lungs & 35.2 & 94.5 & 2.7 \\
7. Heart & 44.0 & 93.8 & 2.1 \\
8. Congenital defects & 40.8 & 97.9 & 2.4 \\
\hline
\end{tabular}

Abbreviation: Gl, gastrointestinal.

examinations were 30 days in the future, it further reinforces the point that the revision of embryology is often only viewed as required to pass examinations. ${ }^{1,10,11}$ There have been calls for an earlier introduction of some elements of embryology (ie, at a school level) to ameliorate the identity of embryology as an area solely for academia. ${ }^{10}$ While an interesting idea, this may face disapproval on the basis that, with the exception of budding medical students, it may influence public opinions on termination of pregnancies. Other groups have tried novel approaches in teaching developmental biology, including an "inquisitive" technique in which students delve into research databases to assimilate answers. ${ }^{12}$

In the capacity of this study, we were not able to change wider attitudes of medical students toward embryology, but we aimed to simplify its teaching to make it more accessible to them. The shortened format allowed students with further interest to explore the ideas discussed, and allowed those who wish to have a "passing" knowledge to further understand the course.

The course itself was the form of a PowerPoint lecture with a 10-minute comfort break between two halves (Figure S1).
Each slide was simple with a limited number of points per page. The commonly examinable parts of the course were highlighted in red. The total delivery time of the course was approximately 110 minutes. Considering the feedback from students, we propose extending the course by a further 10 minutes (total time: 2 hours) to explain early developmental biology and implantation in greater detail, as this was highlighted as an area that the medical students struggled with.

Additionally, students appeared to be less confident with "The processes of fertilization and implantation" and "The development of the neural system." While the course significantly improved confidence in this area, we believe that tailoring the talk to the medical schools and their curricula could have further increased the score. However, the lower scores for these two sections can in part be explained by the fact that human reproduction (the events up to and including placentation) and neurology are taught in the second year of both universities' courses.

Students were significantly more confident with their embryological knowledge after delivery of the course (Tables 1 and 2; Figures 1A-H). Without comments, it becomes difficult to ascertain if this is because the administration of the course reasserted their foundation of knowledge, or if it is because it added to it. The postcourse written comments received make us confident that it is the latter. Over two-thirds of the comments commended the course's facility of simplifying topics that they had previously not understood. Anecdotal feedback from students praised the clear delivery of presenting embryology in this manner, and this is reflected in the postcourse teaching quality questionnaire (Table 3 ).

We have not evaluated the impact of this teaching on medical school examination results as it would not be possible, and we do not feel this is relevant to the core purpose of this teaching. In both medical schools, embryology is taught in the wider course of anatomy and thus any impact 
Table 3 Student scores for delivery of the course (UK, 20I7)

\begin{tabular}{|c|c|c|c|c|}
\hline \multirow[t]{2}{*}{ Question } & \multicolumn{3}{|c|}{ Postcourse $n=\mid 45$} & \multirow[t]{2}{*}{ Interpretation } \\
\hline & Mean & Median & Mode & \\
\hline I. Enjoyable? & 4.45 & 4 & 4 & Agree \\
\hline 2. Content appropriate? & 4.37 & 5 & 5 & Strongly agree \\
\hline 3. Relevant? & 4.48 & 5 & 5 & Strongly agree \\
\hline 4. Well structured? & 4.56 & 5 & 5 & Strongly agree \\
\hline 5. Well taught? & 4.61 & 5 & 5 & Strongly agree \\
\hline 6. High quality? & 4.62 & 5 & 5 & Strongly agree \\
\hline
\end{tabular}

on results is impossible to disentangle. However, it was our view that alleviating the stress traditionally associated with this topic would have wider, unmeasurable, benefits for the medical students.

The initial scoping phase with a focus group of students is likely to be a contributory reason for our ability to effectively design this course. Students were comfortable in telling us, as peers who had recently been through the course, what their difficulties with previous courses were in the intimate focus group environment. They stated that they had found embryology confusing and that, unlike other parts of the course, there was a disconnection with the lecturers who focused more on the science rather than the clinical applications and outcomes. While a previously noted suggestion was the later teaching of embryology, ${ }^{4,6}$ it can be argued that teaching by people from a clinical setting may allow students to see the relevance of the topic, leading to greater engagement.

\section{Conclusion}

We have demonstrated that it is possible to design and produce an embryology teaching program that covers an undergraduate embryology curriculum in a chronological systems-based manner, finishing each system with the clinical consequences of the development processes discussed. We have also shown that it is possible to present this teaching program within a 2-hour time frame. Furthermore, we have demonstrated improvements in student confidence in all aspects of the embryology curriculum following this course when implemented at two different universities.

\section{Author contributions}

Both authors contributed toward data analysis, drafting and critically revising the paper and agree to be accountable for all aspects of the work.

\section{Disclosure}

The study was independently run and subsequently endorsed through the student-run university societies. The authors report no other conflicts of interest in this work.

\section{References}

1. Hamilton J, Carachi R. Clinical embryology: is there still a place in medical schools today? Scott Med J. 2014;59:188-192.

2. Carlson BM. Embryology in the medical curriculum. Anat Rec. 2002;269:89-98.

3. Cassidy KM. Embryology in medical education: a mixed methods study and phenomenology of faculty and first year medical students. 2016.

4. Scott KM, Charles AR, Holland AJA. Clinical embryology teaching: is it relevant anymore? ANZ J Surg. 2013;83(10):709-712.

5. Shankar N, Roopa R. Evaluation of a modified team based learning method for teaching general embryology to 1 st year medical graduate students. Indian J Med Sci. 2009;63:4-12. Available from: http://www. ncbi.nlm.nih.gov/pubmed/19346633. Accessed June 27, 2017.

6. Cassidy KM. Federation proceedings. Federation of American Societies for Experimental Biology; 2015. Available from: http://www.fasebj.org/ content/29/1_Supplement/695.1. Accessed June 27, 2017.

7. Scoville EA, Nyauncho CP, Kumar N, Hassinger JP, Lachman N, Pawlina W. Utilizing peer, near-peer, and inter-professional teaching: A model for integrating embryology into gross anatomy curriculum. Federation of American Societies for Experimental Biology; 2010. Available from: http://www.fasebj.org/content/24/1_Supplement/296.3.short?utm_ source=TrendMD\&utm_medium $=c p c \& u t m \_c a m p a i g n=F A S E B \_J \_$ TrendMD_0. Accessed June 27, 2017.

8. Yu TC, Wilson NC, Singh PP, Lemanu DP, Hawken SJ, Hill AG. Medical students-as-teachers: a systematic review of peer-assisted teaching during medical school. Adv Med Educ Pract. 2011;2:157-172.

9. Bradbury NA. Attention span during lectures: 8 seconds, 10 minutes, or more? Adv Physiol Educ. 2016;40:509-513.

10. Moxham BJ, Emmanouil-Nikoloussi E, Standley H, et al. The attitudes of medical students in Europe toward the clinical importance of embryology. Clin Anat. 2016;29:144-150.

11. Madhuri M, Broussard C. "Do i need to know this for the exam?"; Using popular media, inquiry-based laboratories, and a community of scientific practice to motivate students to learn developmental biology. Cell Biol Educ. 2008;7:36-44.

12. Lu FM, Eliceiri KW, Squirrell JM, White JG, Stewart J. Student learning of early embryonic development via the utilization of research resources from the nematode Caenorhabditis elegans. CBE Life Sci Educ. 2008;7:64-73. 


\section{Supplementary material}

My knowledge of the following topics is...

1) The processes of fertilization and implantation

\begin{tabular}{|l|l|l|l|l|}
\hline Very good & Good & Neither & Poor & Very poor \\
\hline & & & & \\
\hline
\end{tabular}

2) Development of placental support

\begin{tabular}{|l|l|l|l|l|}
\hline Very good & Good & Neither & Poor & Very poor \\
\hline & & & & \\
\hline
\end{tabular}

3) Development of the primary body map (somitogenesis)

\begin{tabular}{|l|l|l|l|l|}
\hline Very good & Good & Neither & Poor & Very poor \\
\hline & & & & \\
\hline
\end{tabular}

4) Principles of organ formation

\begin{tabular}{|l|l|l|l|l|}
\hline Very good & Good & Neither & Poor & Very poor \\
\hline & & & & \\
\hline
\end{tabular}

5) Development of the nervous system

\begin{tabular}{|c|c|c|c|c|}
\hline Very good & Good & Neither & Poor & Very poor \\
\hline & & & & \\
\hline
\end{tabular}

6) Development of the gastrointestinal system and lungs

\begin{tabular}{|l|l|l|l|l|}
\hline Very good & Good & Neither & Poor & Very poor \\
\hline & & & & \\
\hline
\end{tabular}

7) Development of the heart

\begin{tabular}{|c|c|c|c|c|}
\hline Very good & Good & Neither & Poor & Very poor \\
\hline & & & & \\
\hline
\end{tabular}

8) Congenital abnormalities

\begin{tabular}{|c|c|c|c|c|}
\hline Very good & Good & Neither & Poor & Very poor \\
\hline & & & & \\
\hline
\end{tabular}

Figure SI Precourse questionnaire. 
Following this teaching course, my knowledge of the following topics is...

1) The processes of fertilization and implantation

\begin{tabular}{|l|l|l|l|l|}
\hline Very good & Good & Neither & Poor & Very poor \\
\hline & & & & \\
\hline
\end{tabular}

2) Development of placental support

\begin{tabular}{|l|l|l|l|l|}
\hline Very good & Good & Neither & Poor & Very poor \\
\hline & & & & \\
\hline
\end{tabular}

3) Development of the primary body map (somitogenesis)

\begin{tabular}{|l|l|l|l|l|}
\hline Very good & Good & Neither & Poor & Very poor \\
\hline & & & & \\
\hline
\end{tabular}

4) Principles of organ formation

\begin{tabular}{|l|l|l|l|l|}
\hline Very good & Good & Neither & Poor & Very poor \\
\hline & & & & \\
\hline
\end{tabular}

5) Development of the nervous system

\begin{tabular}{|l|l|l|l|l|}
\hline Very good & Good & Neither & Poor & Very poor \\
\hline & & & & \\
\hline
\end{tabular}

6) Development of the gastrointestinal system and lungs

\begin{tabular}{|l|l|l|l|l|}
\hline Very good & Good & Neither & Poor & Very poor \\
\hline & & & & \\
\hline
\end{tabular}

7) Development of the heart

\begin{tabular}{|l|l|l|l|l|}
\hline Very good & Good & Neither & Poor & Very poor \\
\hline & & & & \\
\hline
\end{tabular}

8) Congenital abnormalities

\begin{tabular}{|c|l|l|l|l|}
\hline Very good & Good & Neither & Poor & Very poor \\
\hline & & & & \\
\hline
\end{tabular}

Figure S2 (Continued) 
I enjoyed this course

\begin{tabular}{|l|l|l|l|l|}
\hline Strongly disagree & Disagree & Neither & Agree & Strongly agree \\
\hline & & & & \\
\hline
\end{tabular}

The content of this course was at an appropriate level

\begin{tabular}{|l|l|l|l|l|}
\hline Strongly disagree & Disagree & Neither & Agree & Strongly agree \\
\hline & & & & \\
\hline
\end{tabular}

The information covered in this course was relevant to my learning

\begin{tabular}{|l|l|l|l|l|}
\hline Strongly disagree & Disagree & Neither & Agree & Strongly agree \\
\hline & & & & \\
\hline
\end{tabular}

This course was well structured

\begin{tabular}{|c|c|c|c|c|}
\hline Strongly disagree & Disagree & Neither & Agree & Strongly agree \\
\hline & & & & \\
\hline
\end{tabular}

This course was well taught

\begin{tabular}{|l|l|l|l|l|}
\hline Strongly disagree & Disagree & Neither & Agree & Strongly agree \\
\hline & & & & \\
\hline
\end{tabular}

Overall, this teaching session was of high quality

\begin{tabular}{|c|c|c|c|c|}
\hline Strongly disagree & Disagree & Neither & Agree & Strongly agree \\
\hline & & & & \\
\hline
\end{tabular}

Any additional comments/feedback?

Figure S2 Postcourse questionnaire. 
Advances in Medical Education and Practice

Dovepress

\section{Publish your work in this journal}

Advances in Medical Education and Practice is an international, peerreviewed, open access journal that aims to present and publish research on Medical Education covering medical, dental, nursing and allied health care professional education. The journal covers undergraduate education, postgraduate training and continuing medical education

including emerging trends and innovative models linking education, research, and health care services. The manuscript management system is completely online and includes a very quick and fair peer-review system. Visit http://www.dovepress.com/testimonials.php to read real quotes from published authors.

Submit your manuscript here: http://www.dovepress.com/advances-in-medical-education-and-practice-journal 